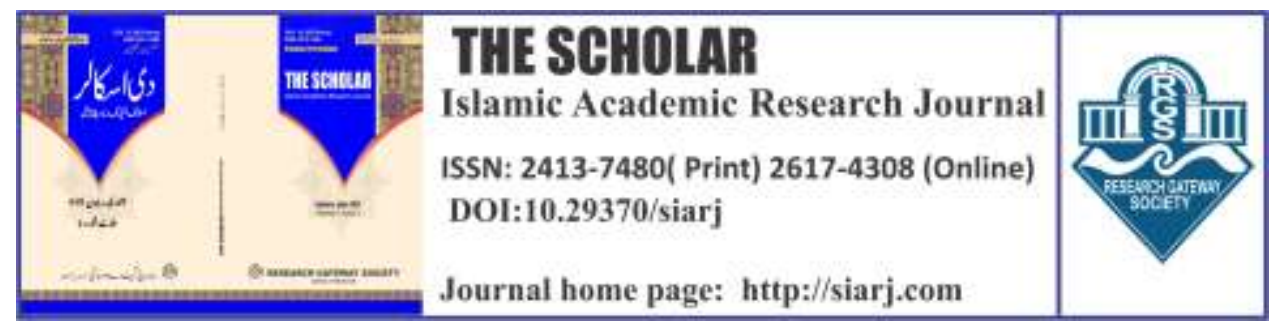

$$
\begin{aligned}
& \text { محاولة لتصحيح الأخطاء الإسنادية التي وقعت في المعجم الأوسط للإمام سليمان بن } \\
& \text { أحمد الطبراني (دراسـة في علم علل الحديث) }
\end{aligned}
$$

\title{
AN ATTEMPT TO CORRECT THE CREDENTIALS ERRORS OCCURRED IN AL- (A CRITICAL STUDY OF MU'JAM AL-AWSAT WRITTEN BY IMAM AL-TABRANI HADITH)
}

\section{Sayyed wali Ullah shah}

Ph.D., Research scholar Faculty of Usoluddin

Department of Hadith and it's sciences

International Islamic University Islamabad.

Email:syediiui@gmail.com

ORCID ID:

https://orcid.org/0000 000286575440

To cite this article:

Shah, Sayyed wali Ullah, and Masood Ahmed. "ARABIC-AN ATTEMPT TO CORRECT THE CREDENTIALS ERRORS OCCURRED IN AL-MU'JAM AL-AWSAT WRITTEN BY IMAM ALTABRANI (A CRITICAL STUDY OF HADITH)." The Scholar-Islamic Academic Research Journal 7, No. 2 (December 29, 2021).

To link to this article: https://doi.o rg/10.29370/siarj/issue13arabic4

Journal

Publisher

DOI:

URL:

License:

Journal homepage

Published online:
The Scholar Islamic Academic Research Journal Vol. 7, No. 2 || July -December 2021 || P. 71-90 Research Gateway Society 10.29370/siarj/issue13arabic4 https://doi.org/10.29370/siarj/ issue13arabic4 Copyright c 2017 NC-SA 4.0 www.siarj.com 2021-12-29
2. Masood Ahmed

Assistant professor, International Islamic

University, Islamabad.

Email: masood.ahmed@iiu.edu.pk

ORCID ID:

https://orcid.org/0000-0002-9804-8314 


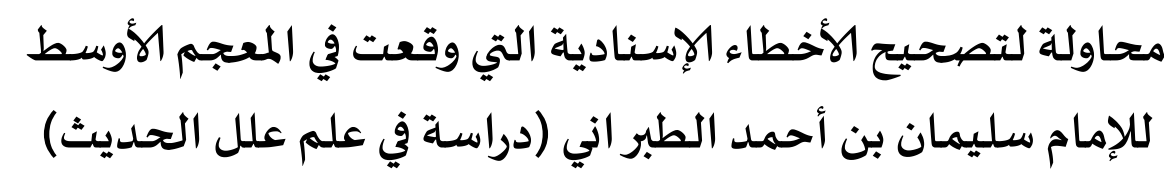

AN ATTEMPT TO CORRECT THE CREDENTIALS ERRORS OCCURRED IN AL-MU'JAM AL-AWSAT WRITTEN BY IMAM ALTABRANI (A CRITICAL STUDY OF HADITH)

\author{
Sayyed wali Ullah shah, Masood Ahmed
}

\title{
ABSTRACT:
}

Imam Sulaiman bin Ahmad Al-Tabarani was a famous Muhaddith of 3rd and 4th century $\mathrm{AH}$. He has significant services in the field of "Ilm ul Elal". His famous book in this regard is "Al-Mujam Al Awsat". He has explained the "Al-Elal" of ahadith in this book. He mentioned "Elal" are based on the differences and disagreements of the narrators. The said book is unique in this regard; however, there are errors in same places. A critical research study of its five hundred (500) ahadith has found thirty-six (36) errors in it. Most of the errors are found in the credentials. These include errors in narrator's names, their father names, and errors in the credentials. These errors are mentioned in the article. Arguments have been given regarding these errors. This research invites a critical research study of this book in this regard, so that it can be corrected. This article is divided into preface and nine axes and conclusion. The preface shows the importance of the said critical study of "Al-Mu'jam Al-Awsat" in this regard, and the axes are showing the different kinds of these errors.

KEYWORDS: Imam Al-Tabarani, Al-Mu'Jam Al-Awsat, Elal AlHadith.

$$
\text { الكلمات المفتاحية: المعجم الأوسط، سليمان بن أحمد الطبراني، علل الحمديث. }
$$


يعد الإمام سليمان بن أحمد الطبراني من محدثي القرنين؛ الثالث والرابع الهجري الذين لهم

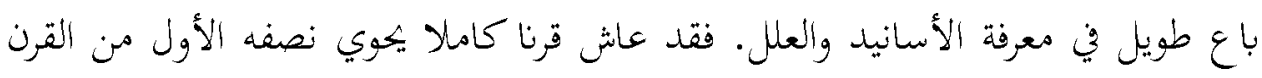

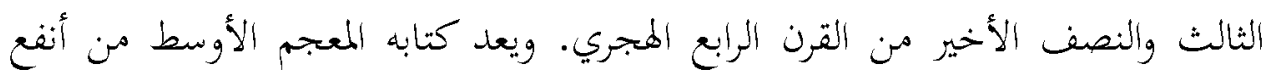

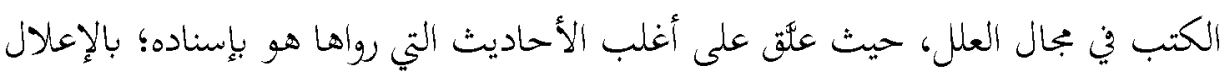

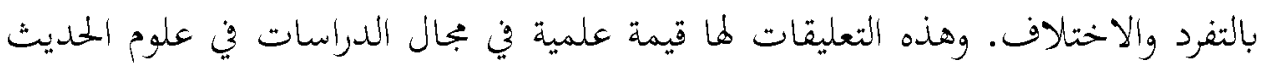

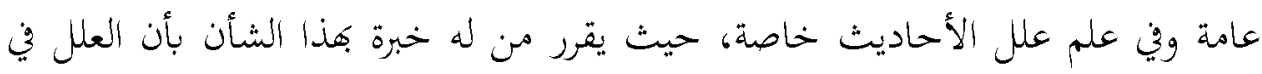

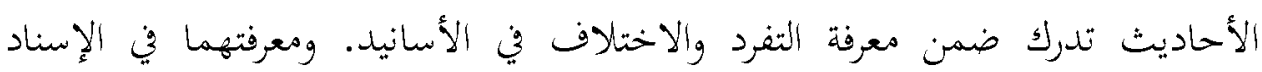

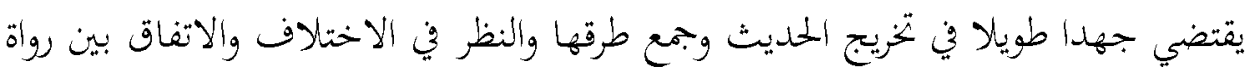

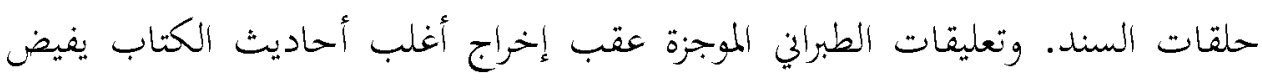

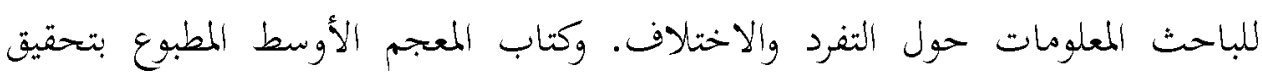

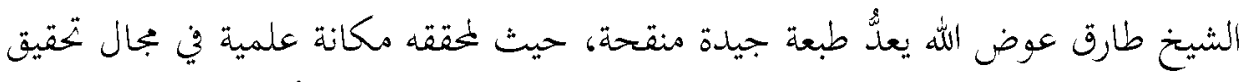

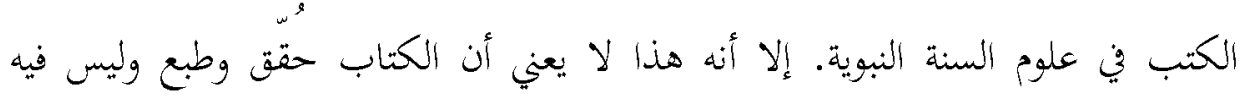

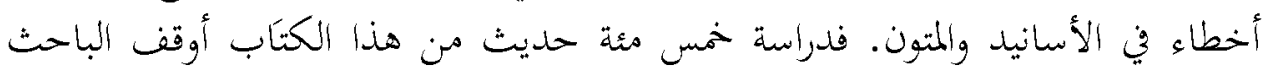

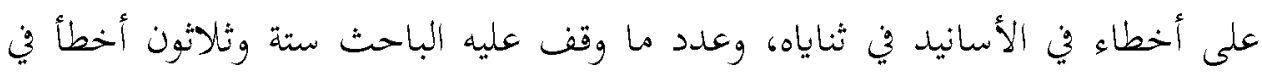

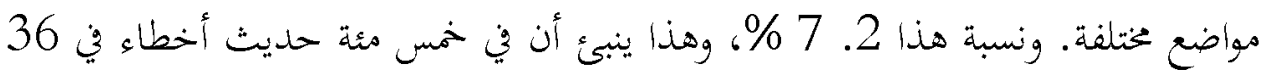
حديث، فكيف في الكتاب بتمامهوهذه الأخطاء في الأسانيد ينقسم إلى أخطاء في أسماء

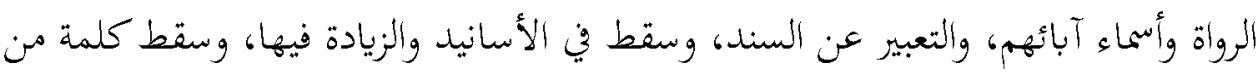

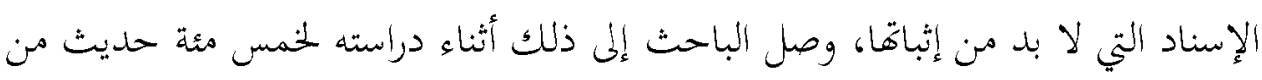

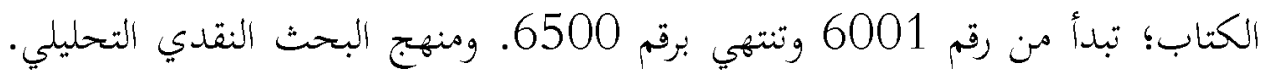
وهو مشتمل على تسعة محاور، وخلاصة البحث والتوصيات، وبالله التوفيق. العهور الأول: الأخطاء في أسماء الرواة:

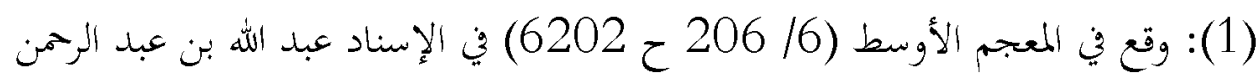

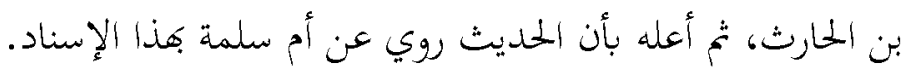

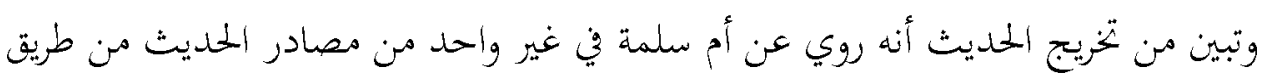




$$
\begin{aligned}
& \text { ابن إسحاق، وفي إسناده اضطراب عن ابن إسحاق. ففي بعض الطرق: عبد الملك بن } \\
& \text { الحارث بن هشام، وفي بعضها: عبد الرحمن بن الحارث، ولم أجده من طريق عبد الله بن }
\end{aligned}
$$

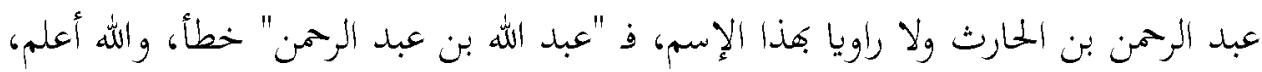

$$
\begin{aligned}
& \text { والصواب عبد الملك أو عبد الرحمن بن الحلارث. }
\end{aligned}
$$

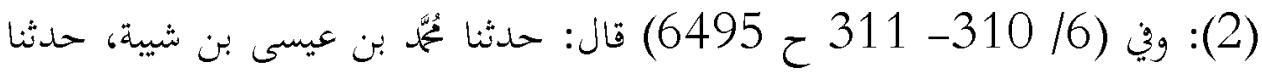

$$
\begin{aligned}
& \text { الحسن بن علي الاحتياطي.. الحديث. ولم أجد في الرواة من المهه الحسن بن علي }
\end{aligned}
$$

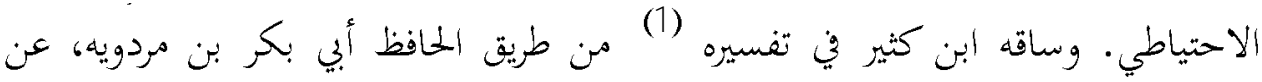

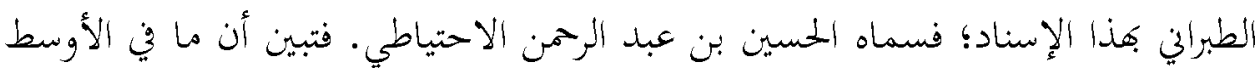

$$
\begin{aligned}
& \text { خطأ، والصواب الحسين بن عبد الرحمن الاحتياطي. } \\
& \text { (3): وي (6322 } 251 \text { (632): يميى بن يزيد الأصم، قال: سمعت السدي... } \\
& \text { الحديث. ثم أعله بتفرد يهيى بن يزيد عن السدي. }
\end{aligned}
$$

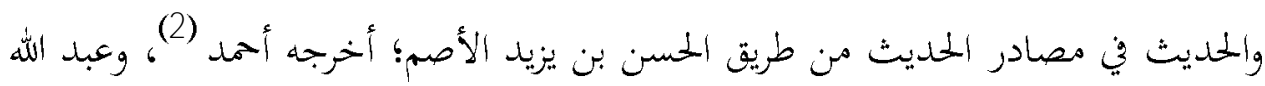

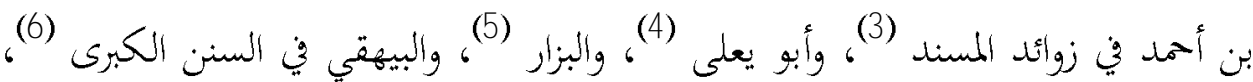

${ }^{1}$ Tafseer-ul-Quran, Ismaeel bin Umar Al-Damashqi, Abu Al-Fida, Dar-eIbne Hazam, Beirut, 1420, P. 227- 228

${ }^{2}$ Musnad Ahmad bin Hanbal, Al-Sheebani, Abu Abdullah, Edited by: AlSayyed Abu Al-Mu'ati, Al-Noori, Alamul Kutub, Beirut, 1419, Vol: 1, P. 103, Hadith No. 807

${ }^{3}$ Musnad Ahamad, Vol: 1, P. 129, Hadith No. 1084

)$^{4}$ ( Musnad Abi Ya'la, Ahmad bin Ali Al-Tameemi, Al-Mosili, Abu Ya'la, Edited by: Husain Saleem Asad, Darul Mamoon, Damascus, 1404, Vol: 1, P. 335, Hadith No. 424

)$^{5}$ ( Al-Bahr-uz-Zakhar, (Musnad Al-Bazzar), Ahmad bin Amr Al-Bazzar, Abu Bakr, Edited by: Mahfooz-ur-Rahman Zain Ullah, Adil bin Sa'ad and Sabri Abdul Khaliq Al-Shafi'e, Maktaba Al-Uloom Wal-Hikam, Madina, 2009 AD, Vol: 2, P. 207, Hadith No. 592

)$^{6}$ ( Al-Sunan Al-Kubra, Ahmad bin Al-Husain Al-Behaqi, Edited by: Muhammad Abdul Qadir Ata, Darul Kutub Al-Elmiya, Beirut, 1424, Vol: 1, P. 455 


$$
\begin{aligned}
& \text { وابن عدي في الكامل (7) كلهم بطرق عن الحسن بن يزيد الأصم. ومن جملة الطرق سعيد }
\end{aligned}
$$

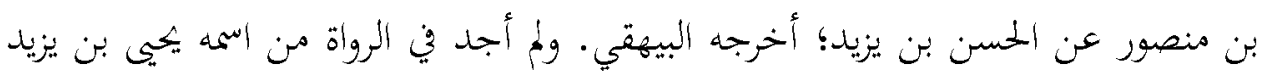

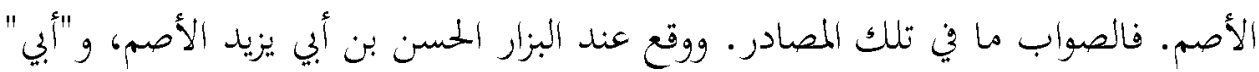

$$
\begin{aligned}
& \text { أيضا خطأُ، و الله أعلم. } \\
& \text { (4): في (6/6 } 208 \text { ح 6206) عن علي بن زيد (ابن جدعان)، عن أبي أويس، عن أبي } \\
& \text { هريزة. } \\
& \text { وهو أبو أوس، وليس بأبي أويس. ذكره أبو أحمد الحاكم في الأسامي والكنى (8)، وابن منده }
\end{aligned}
$$

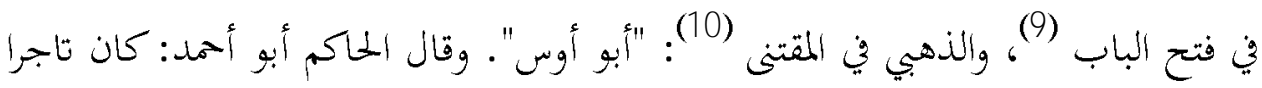

$$
\begin{aligned}
& \text { بالمدينة، واستند إلى هذا الإسناد -إسناد الطبرائ- وذكر ابن منده والذهبي الراوي عنه: }
\end{aligned}
$$

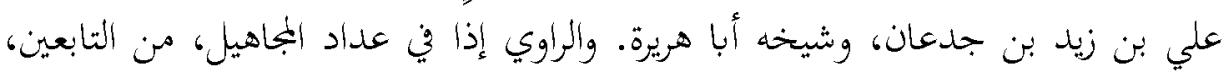

$$
\begin{aligned}
& \text { والصواب في كنيته أبو أوس. } \\
& \text { (5): ووقع في (64/294 ح 6453) عبد الله بن قدامة الجمحي في الإسناد، يروي عن } \\
& \text { أبيه عن جده، عن أبي بكر الصديق. وهو خطأ ليس لقدامة ابن باسم عبد الله، وله ثلاثة } \\
& \text { بنون؛ إبراهيم، وصالح وعبد الملك. وإنا هو عبد الملك في هذا الإسناد. لأنه وقع عنده } \\
& \text { على الصواب في (6/6 298- } 299 \text { ح 6463) بالإسناد نفسه عن أبي بكر الصديق. }
\end{aligned}
$$

)$^{7}$ ( Al-Kamil fi Dhuafa Al-Rijal, Abu Ahmad bin Adi Al-Jurjani, Edited by: Adil Ahmad Abdul Mujood and Ali Muhammad Mu'awidh, Darul Kutub Al-Elmiya, Beirut, 1418, Vol: 3, P. 173

)$^{8}$ ( Al-Asami wal Kuna, Muhammad bin Muhammad Al-Neesaboori, AlHakim Al-Kabir, Edited by: Abu Umar Muhammad bin Ali Al-Azhari, AlFarooq Al-Hadithiya, cairo, 1436, P. 314

) ${ }^{9}$ ( Fathul Bab fi Al-Kuna wa Alqab, Muhammad bin Ishaq, Ibn-e-Manda, Al-Asbahani, Edited by: Abu Qutaiba Nazar Muhammad Al-Faryabi, Maktaba Al-Kauthar, Riyadh, 1417, P. 103

)$^{10}$ ( Al-Muqtana fi Sard Al-Kuna, Muhammad bin Ahmad, Al-Zahabi, Edited by: Muhammad Salih Abdul Aziz Murad, Al-Majlisul Elmi, Madinah University, Madinah, Vol: 1, P. 97 


$$
\begin{aligned}
& \text { (6): وفي (229- } 230 \text { ح 6263) وقع اسم الراوي في الإسناد "جابر بن غيلان } \\
& \text { بن منبه الصنعاني" والصواب "غوث بن جابر بن غيلان..." لأن الحمديث أخرجه في الكبير } \\
& \text { (11) مطولا، وفي إسناده غوث بن غيلان بن منبه الصنعاني، فنسبه إلى جده الأعلى. }
\end{aligned}
$$

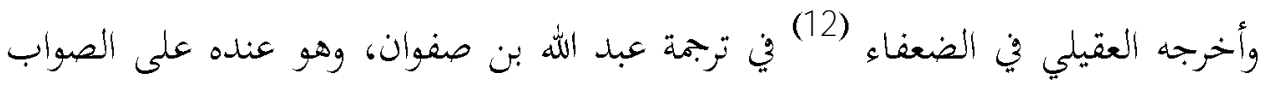

$$
\begin{aligned}
& \text { غوث بن جابر بن غيلان. ونَّه محقق كتاب المعجم الأوسط على هذا الخطأ. ودول على } \\
& \text { الأصل بأنه وقع فيه كذا على الخطأ. } \\
& \text { (7): وين (16 251- } 252 \text { ح 6324) وقع اسم الراوي في الإسناد "حبيب بن عبد } \\
& \text { الرحمن" بالحاء المهملة. وهو خطأ؛ اسمه خبيب بالخناء المعجمة ابن عبد الرحمن الأنصاري، }
\end{aligned}
$$

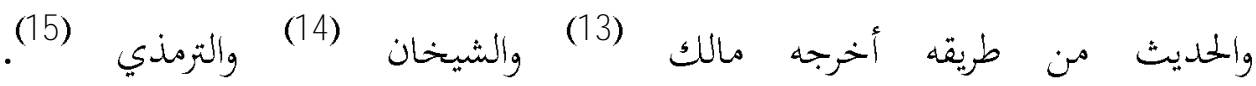




$$
\begin{aligned}
& \text { محاولة لتصحيح الأخطاء الإسنادية التي وقعت في المعجم الأوسط للإمام سليمان } \\
& \text { بن أحمد الطبراني (دراسـة في علم علل الحديث) } \\
& \text { (8): وفي (198/6 (199 ح 6180) ساق الإسناد من طريق هيثم الحناء، نا أبو } \\
& \text { علي الرحبي... وقال في التعليق: تغرد به أبو علي الرحبي؛ وهو حسين بن عبد الله بن عبيد } \\
& \text { الله بن العباس بن عبد المطلب. } \\
& \text { فخالف ما في الإسناد، وذلك بأن اللذي المهه حسين بن عبد الله المدني وكنيته أبو عبد الله } \\
& \text { (16)، وأبو علي الرحبي هو الحسين بن قيس الرحبي الواسطي الملقب بحنش ، وهو الصواب }
\end{aligned}
$$

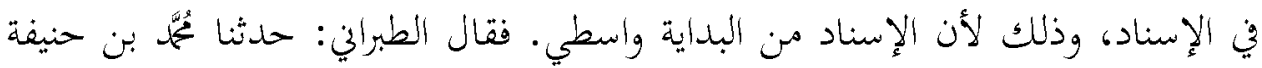

$$
\begin{aligned}
& \text { الواسطي، قال: نا حفص بن عمر الرازي، قال: نا ثئمّم بن عبادة الواسطي، قال: نا هيثم } \\
& \text { الحذاء، قال: نا أبو علي الرحبي، عن عكرمة، عن ابن عباس. وحفص بن عمر الرازي }
\end{aligned}
$$

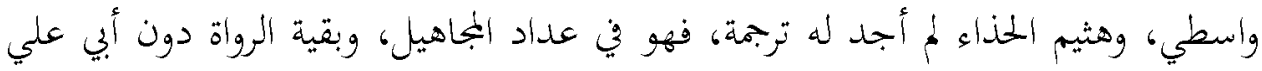

$$
\begin{aligned}
& \text { الرحبي كلهم واسطيون، أما المعرَّف في التعليق، فهو مدئي. وكالاهما يرويان عن عكرمة، } \\
& \text { وكالاهما متروكان، و الله أعلم. } \\
& \text { (9): وي (6/6 } 150 \text { ح 6052) أخرج الحديث من طريق إسماعيل بن سليمان عن } \\
& \text { القاسم بن صفوان. } \\
& \text { وذكر ابن أبي حاتم في الجمح والتعديل (17) أن القاسم بن صفوان عرف برواية بشير بن } \\
& \text { سليمان عنه، ولم يرو عنه غيره. وذكر البخاري في التاريخ الكبير (18) الشعبي وأشعث أيضا } \\
& \text { في الرواة عن القاسم بن صفوان. والحديث أخرجه ابن أبي شيبة، من طريق بشير بن }
\end{aligned}
$$

)$^{16}$ ( Tahzeeb Al-Kamal fi Asma Al-Riajal, Yousaf bin Abdul Rahman, AlMizzi, Edited by: Dr.Basshar Awad Ma'roof, Mu'assisa Al-Risalah, Beirut, 1400, Vol: 6, P. 383

17 Al-Jarh wal-Ta'adeel, Abdul Rahman bin Muhammad Al-Razi, Majlis Daera Al-Ma'arif Al-Uthmaniya, Haidarabad India, Vol: 7, P. 111

18 Al-Tarikh Al-Kabir, Muhammad bin Isma'eel Al-Bukhari, Daera AlMa'arif Al-Uthmaniya, Haidarabad India, Vol: 7, P. 161 


$$
\begin{aligned}
& \text { محاولة لتصحيح الأخطاء الإسنادية التي وقعت في المعجم الأوسط للإمام سليمان } \\
& \text { بن أحمد الطبراني (دراسـة في علم علل الحديث) } \\
& \text { سليمان، عن رجل هن الأنصار، عن أبيه (19). والرجل المبهم هو القاسم بن صفوان، لأن }
\end{aligned}
$$

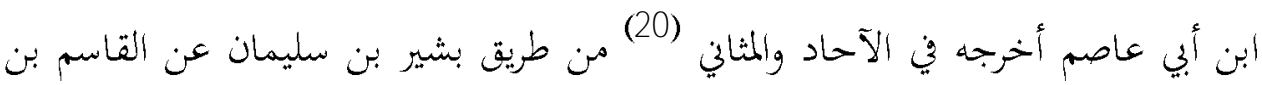

$$
\begin{aligned}
& \text { صفوان عن أبيه. فإسماعيل بن سليمان خطأ والصواب بشير بن سليمان، و الله أعلم. } \\
& \text { (10): وفي (6/6 248 ح 2314) وقع في الإسناد عبد الرحن بن السفر الدمشقي، } \\
& \text { يروي عن الأوزاعي. } \\
& \text { وجاء في تاريخ دمشق لابن عساكر (21) أن اسم الراوي هو يوسف بن السفر أبو الفيض، } \\
& \text { وهو كاتب الأوزاعي، يروي عنه. لكن أحد الرواة -وهو سعيد بن يعقوب الطالقاني، وهو } \\
& \text { الراوي عن عبد الرحمن بن السفر في هذا الحديث عند الطبراني-، فوقع عنده عبد الرحمن } \\
& \text { بن السفر، وعبد الرحمن بن السفر لا يعرف، واسم الراوي الصحيح هو يوسف بن الفيض، } \\
& \text { أو يوسف بن السفر أبو الفيض. وبيّن ذلك ابن عساكر في تاريخه في الموضع المنكور أن } \\
& \text { الراوي الآخر يروي عنه هذا الحديث ويسمه يوسف بن الفيض. وجاء في جزء البيبي } \\
& \text { أن شيخها ابن صاعد وقف عند هذا الاسم وصحَّحه قال: يوسف بن السن السفر أبو الفيض. } \\
& \text { على أن ابن حجر حينما ترجم ليوسف بن الفيض أو يوسف بن السفر في اللسان، }
\end{aligned}
$$

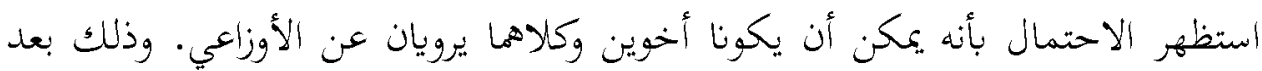

19 Al-Musannaf, Abdullah bin Muhammad bin Abi Sha'eba, Edited by: Muhammad Awwama, Darul Qiblah, Jeddah, 1427, Vol: 4, P. 276, Hadith No. 5999

${ }^{20}$ Al-Aa'had wal-Mathani, Ahmad bin Amr, Al-Sheebani, Abu Bakar bin Abi A'asim, Edited by: Dr.Basim Faisal Ahmad Al-Jawabira, Darul Raya, Riyadh, 1411, Vol: 4, P. 217, Hadith No. 2202

${ }^{21}$ Tarekh-e-Damascus, Ali bin Al-Hasan Al-Shafi'e, Ibn-e-Asakir, Edited by: Umar bin Gharama Al-Umravi, Darul Fikar, Beirut, 1415, Vol: 35, P. 195

22 Juz'e Bibi Bint Abdul Samad Al-Harthamiya, Edited by: Abdul Rahman Al-Fariwa'e, Darul Khulafa lil Kitab Al-Islami, 1406, P. 56, Hadith No. 64 


$$
\begin{aligned}
& \text { محاولة لتصحيح الأخطاء الإسنادية التي وقعت في المعجم الأوسط للإمام سليمان } \\
& \text { بن أحمد الطبراني (دراسة في علم علل الحديث) } \\
& \text { اطلالع على ما في تاريخ دمشق من أنه لا يعرف. (23) }
\end{aligned}
$$

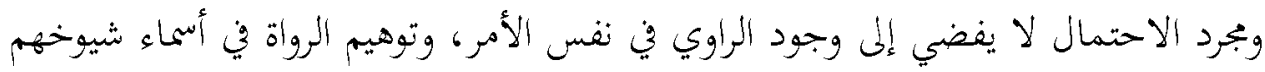

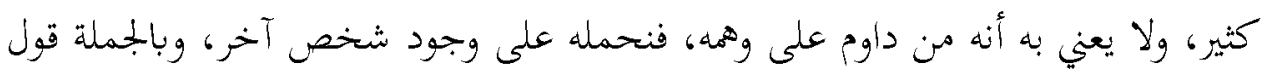

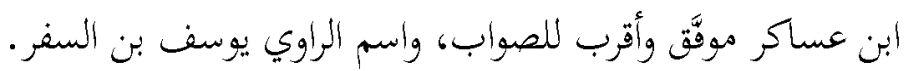

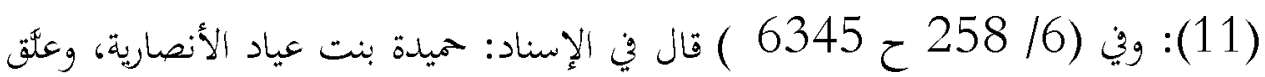

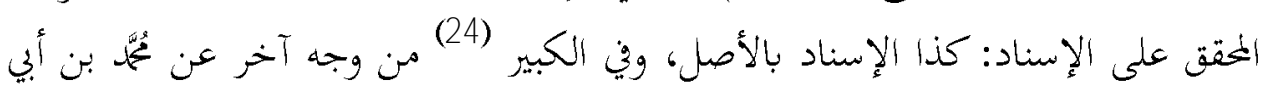

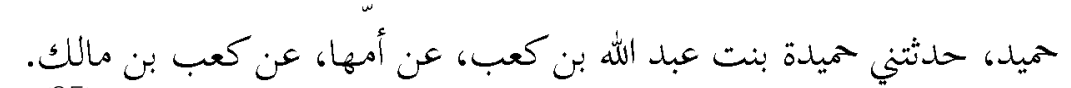

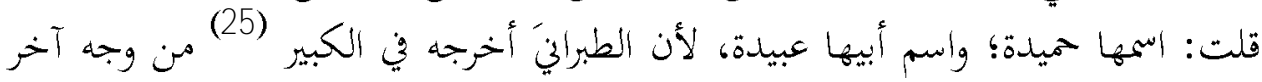

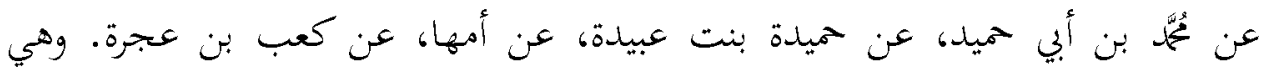

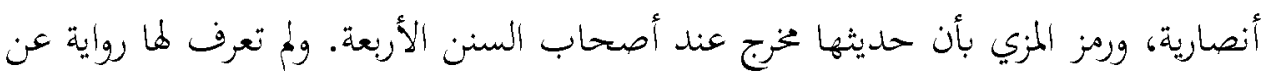

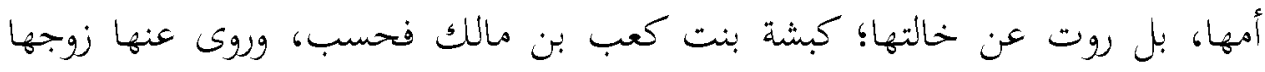

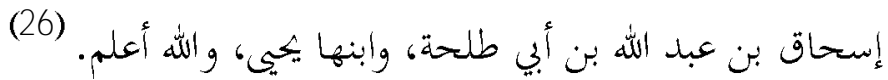

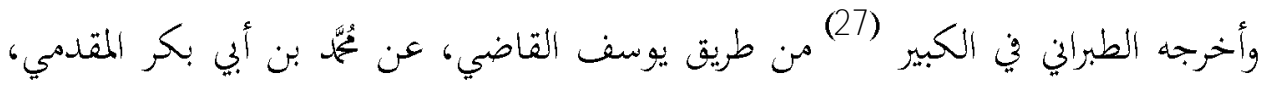

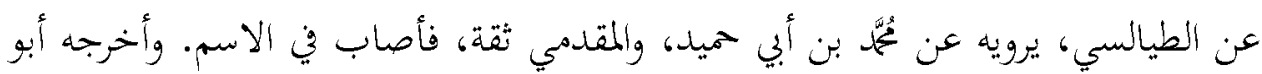

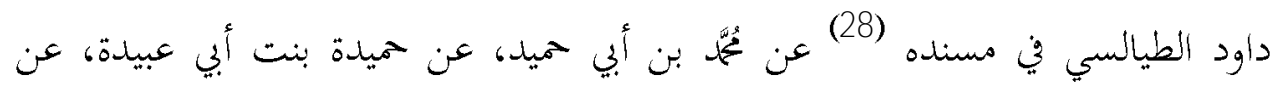

$$
\begin{aligned}
& \text { أمها، عن كعب بن مالك، فذكره بكنيته. }
\end{aligned}
$$

${ }^{23}$ Lisan ul-Meezan, Ahmad bin Ali bin Hajar, Al-Asqalani, Edited by: Abdul Fattah Abu Ghudda, Darul Basha'ir Al-Islamia, Beirut, 2002 AD, Vol: 5, P. 105

${ }^{24}$ Al-Mu'jam Al-Kabir, Al-Tabarani, Vol: 19, P. 103

${ }^{25}$ Al-Mu'jam Al-Kabir, Al-Tabarani, Vol: 19, P. 162

${ }^{26}$ Tahzeeb Al-Kamal, Vol: 35, P. 159

${ }^{27}$ Al-Mu'jam Al-Kabir, Al-Tabarani, Vol: 19, P. 162

${ }^{28}$ Musnad Abi Dawood Al-Thayalisi, Sulaymān ibn Dāwūd Al-Thayalisi, Abu Dawood, Edited by: Dr.Muhammad bin Abdul Muhsin Al-Tuki, Published at: Dar-e-Hijar, Egypt, 1419, Vol: 2, P. 300, Hadith No. 1035 


$$
\begin{aligned}
& \text { محاولة لتصحيح الأخطاء الإسنادية التي وقعت في المعجم الأوسط للإمام سليمان } \\
& \text { بن أحمد الطبراني (دراسـة في علم علل الحديث) } \\
& \text { وقيل: السمه عبد الله بن كعب، كما في إسناد الطبراني في الكبير (29). وفي إسناده زيد بن إسن } \\
& \text { الحريش رواه عن الطيالسي، عن مُعمّ بن أبي حميد، قال ابن حبان في الثقات: ربما أخطأ، } \\
& \text { وقال ابن القطان: مجهول الحال، فلعل الخطأ منه. } \\
& \text { ويمتمل -احتمالا قويا- أن يكون الخطأ في اسم أبيها من مُّمَّم بن أبي حميد، لأنه كان }
\end{aligned}
$$

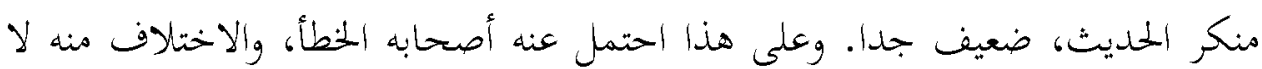

$$
\begin{aligned}
& \text { عليه. (30) } \\
& \text { واسم حمدة تصحف لدى الهيثمي في المجمع (31)؛ فسماها حمدة بنت عبيد، فأصاب في } \\
& \text { اسم أبيها، وأخطأ في اسمها. } \\
& \text { فتبين محا سبق بيانه أن الصواب في اسم أبي حميدة: عبيدة، و الله أعلم. } \\
& \text { المحور الثاني: إبدال راو براو آخر آئي } \\
& \text { (12): وفي (16/157 ح 6073) أخرج الحديث من طريق مسلم بن إبراهيم، عن حماد } \\
& \text { بن زيد، عن عبد الرحمن بن إسحاق، وأعله بتغرد مسلم بن إبراهيم، عن حماد بن زيد. }
\end{aligned}
$$

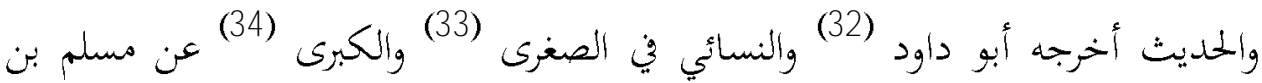

${ }^{29}$ Al-Mu'jam Al-Kabir, Al-Tabarani, Vol: 19, P. 103

${ }^{30}$ Al-Tārīkh Al-Kabīr, Vol: 1, P. 70, Al-Kamil, Ibne Adi, Vol: 7, P. 410440, Tahzeeb Al-Kamal, Vol: 25, P. 112- 115

31 Majma Al-Zawa'id wa Manba' Al-Fawa'id, Ali bin Abi Bakr, AlHaythami, Edited by: Hussamud' Din Al-Qudsi, Maktaba Al-Qudsi. Cairo, 1414 AH, Vol: 3, P. 177

${ }^{32}$ Sunan Abī Dāwūd, Sulaymān ibn al-Ash'ath Al-Sijistān̄̄, Abū Dāwūd, Edited by: Esam Musa Hadi, Published at: Daru' Al-Siddique, Al-Jubail, Saudi Arabia, 1434 AH, Vol: 6, P. 327- 328, Hadith No. 4272

${ }^{33}$ Sunan An-Nasa'i Al-Sughra, Ahmad bin Shu'aib An-Nasai, Abu Abdur Rahman, Edited by: Abdul Fattah Abu Ghudda, Published at: Maktab AlMatbu'at Al-Islamia, Aleppo, 1406 AH, Vol: 7, P. 87

${ }^{34}$ Sunan An-Nasa'i Al-Kubra, Ahmad bin Shu'aib An-Nasai, Abu Abdur Rahman, Edited by: Hasan Abdul Mun'em Shalabi, Publish at: Mu'assa Al-Risala, Beirut, 1421 AH, Vol: 3, P. 423, Hadith No. 3457 


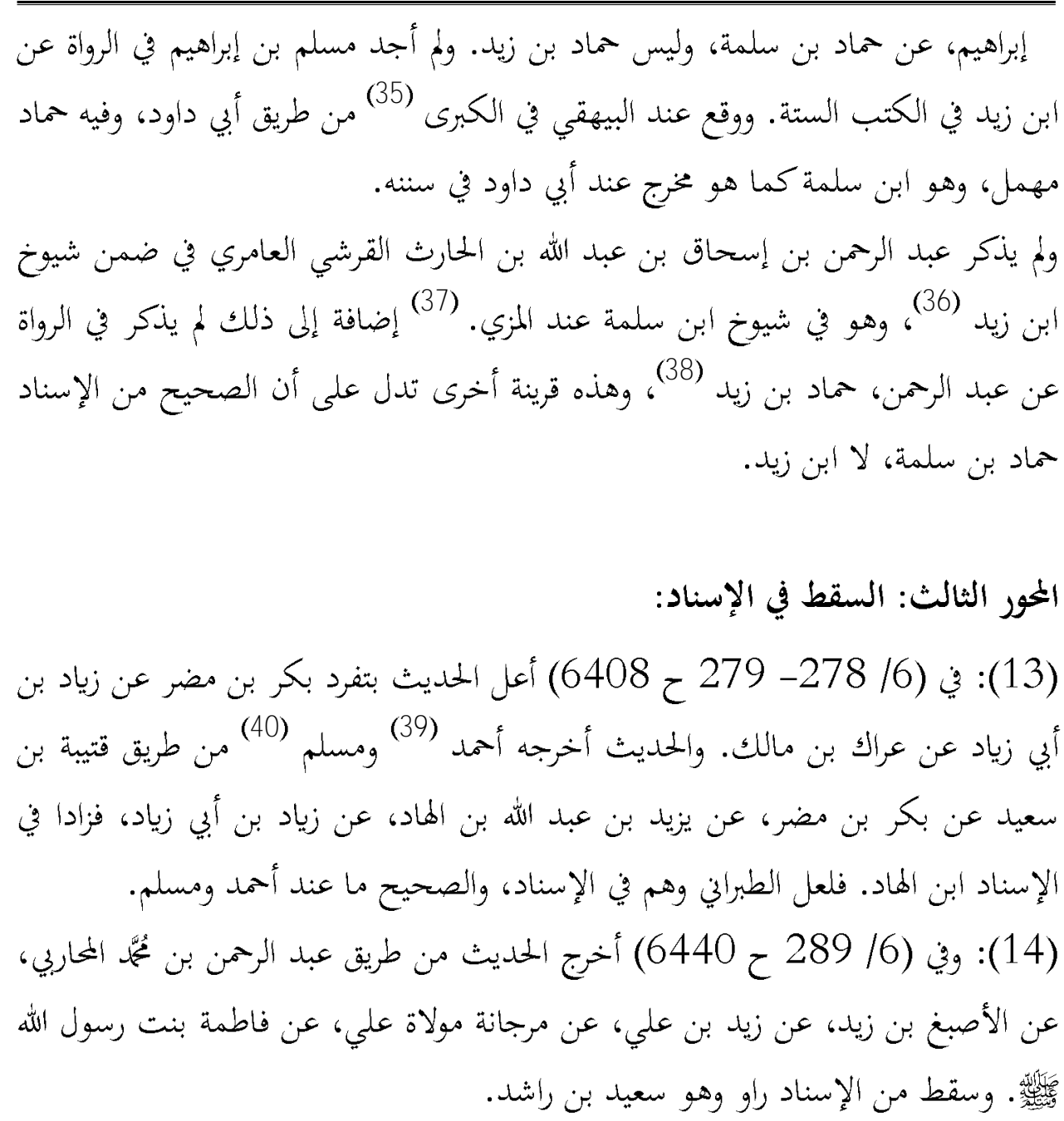

${ }^{35}$ Al-Sunan Al-Kubra, Al-Behaqi, Vol: 8, P. 29

36 To Know the sheikhs of Hammad bin Zaid See; Tahzeeb Al-Kamal, Vol: 7, P. 239- 242

${ }^{37}$ Tahzeeb Al-Kamal, Vol: 7, P. 254- 256

${ }^{38}$ Hammad bin Zaid, Tahzeeb Al-Kamal, Vol: 7, P. 242- 245

${ }^{39}$ Musnad Ahmad, Vol: 6, P. 92, Hadith No. 25118

${ }^{40}$ Sahih Muslim, Vol: 8, P. 38, Hadith No. 6787 


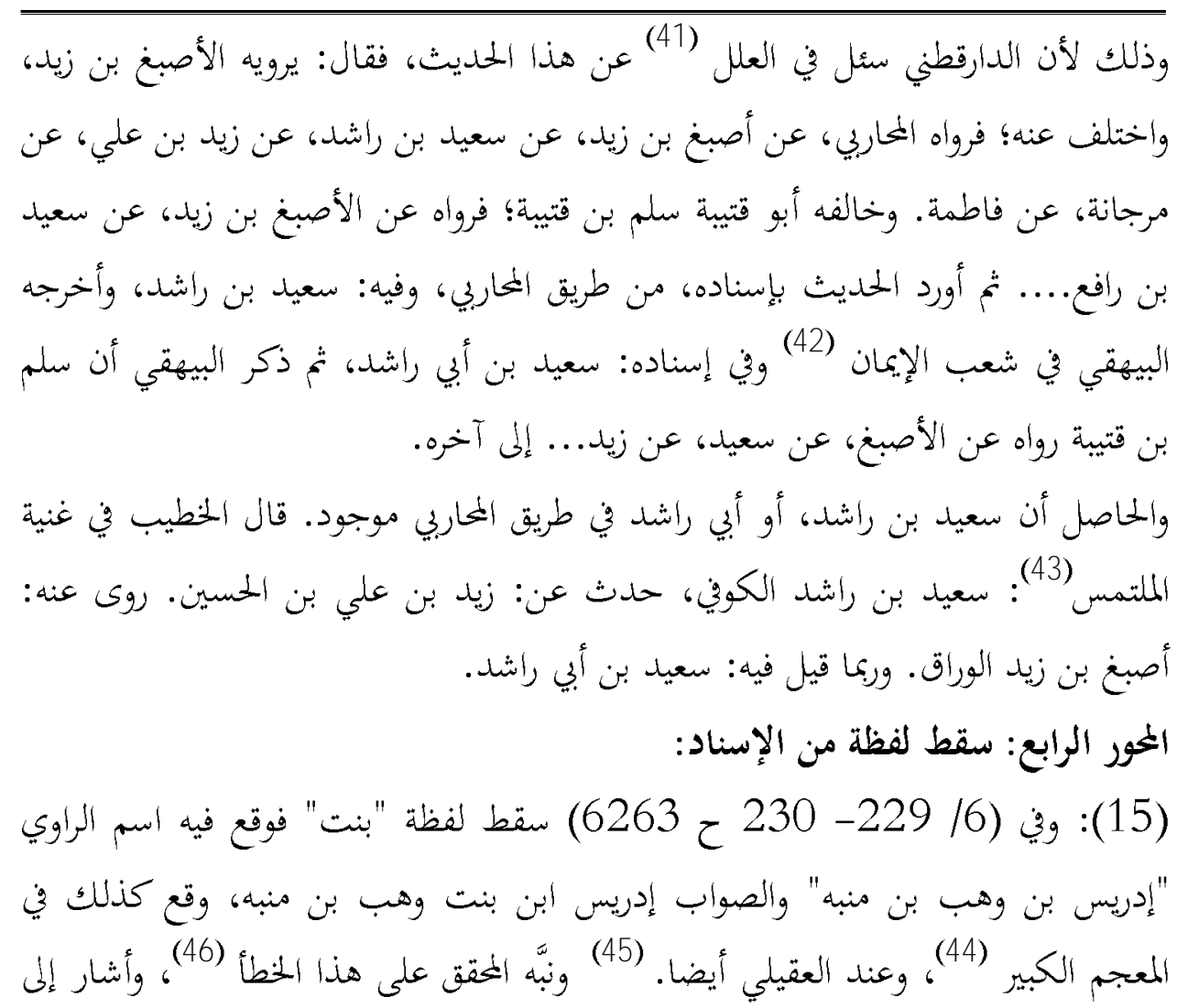

41 Al-'Ilal Al-Warida fi Al-Ahadith An-Nabawiya, Ali ibn Umar AlDaraqutni, Abu Al-Hasan, Edited by: Mahfuz Ur-Rahman Zain Ullah AlSalafi, Published at: Dar-e-Tayba, Riyadh, 1405 AH, Vol: 5, P. 175- 176 ${ }^{42}$ Shu'ab Al-Eman, Ahmad bin Al-Husain Al-Behaqi, Edited by: Dr.Abdul Ali Abdul Hamid Hamid, Published at: Maktaba Al-Rushd, Riyadh, 1423 AH, Vol: 4, P. 399, Hadith No. 2716

${ }^{43}$ Ghunyat Al-Multamis wa Eezahul Al-Mutalabbis, Ahmad bin Ali AlKhatib Al-Baghdadi, Edited by: Dr.Yahya bin Abd Ullah Al-Bikri AlShahri, Published at: Maktaba Al-Rushd, Riyadh, 1422 AH, P. 199

${ }^{44}$ Al-Mu'jam Al-Kabir, Al-Tabarani, Vol: 11, P. 55, Hadith No. 11027

${ }^{45}$ Al-Duafa, Al-Uqaili, Vol: 3, P. 251

${ }^{46}$ Al-Mujam Al-Awsat, Vol: 6, P. 229 
${ }^{47}$ Silsilatul Al-Ahadith Al-Sahiha wa Sha'un min Fiqhiha wa Fawaidiha, Muhammad Nasir Ud-Din Al-Albani, Published at: Maktaba Al-Ma'arif lin-Nashre wat-Tozee'i, Riyadh, Vol: 6, P. 233- 234, Hadith No. 2619 ${ }^{48}$ Majma Al-Zawa'id, Al-Haythami, Vol: 3, P. 242- 243 


$$
\begin{aligned}
& \text { المحور الخامس: الخطأ في اسم أب الراوي أو اسم جده: } \\
& \text { (18): في (6/ } 206 \text { ح 6201) وقع اسم الراوي الحكم بن بشير بن سليمان، وهو }
\end{aligned}
$$

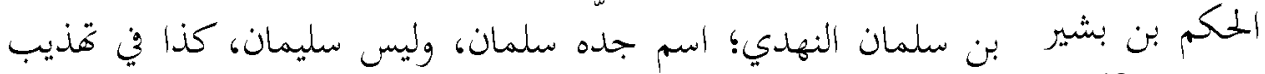

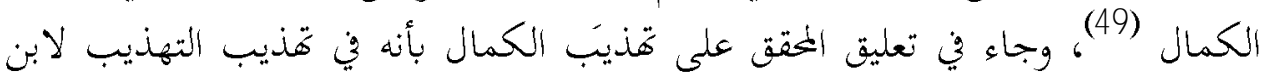

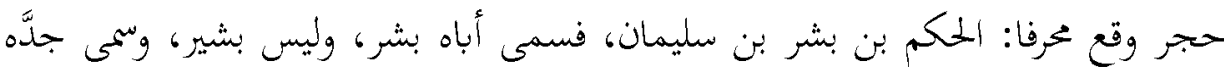

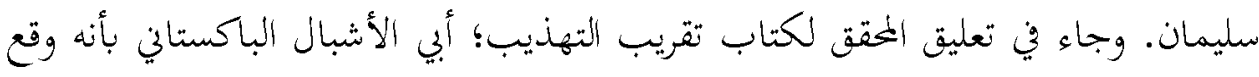

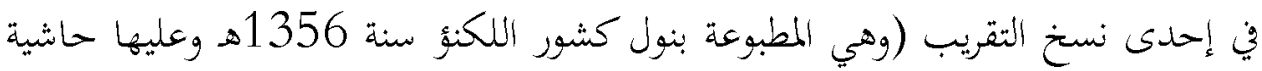

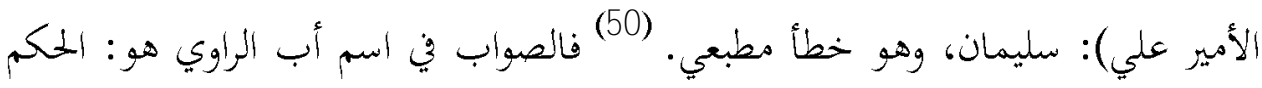

$$
\begin{aligned}
& \text { بن بير بن سلمان. } \\
& \text { (19): وفي (16 } 207 \text { ح 6203) وقع في الإسناد والتعليق اسم الراوي المارث بن عبيد } \\
& \text { أبو قدامة، وهو خطأ؛ والصواب: الحارث بن غسان، ووقع على الصواب عنده في }
\end{aligned}
$$

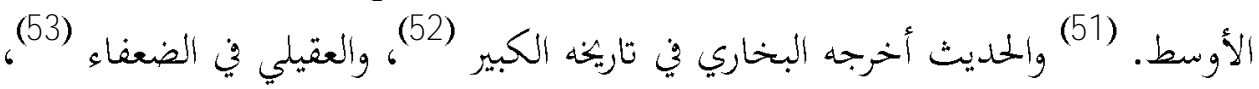

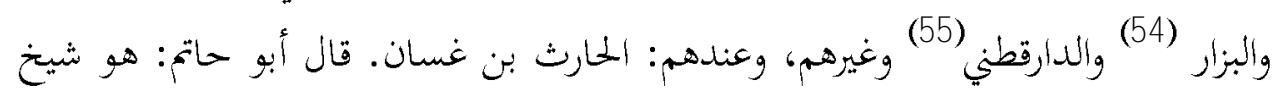

$$
\begin{aligned}
& \text { مجهول يروي عن أبي عمران الجموني. }
\end{aligned}
$$

${ }^{49}$ Tahzeeb Al-Kamal, Vol: 7, P. 89

${ }^{50}$ Taqreebu' Al-Tahzeeb, Ahmad bin Ali bin Hajar Al-Asqalani, Edited by: Abu Al-Ashbal Shaghif Pakistani, Published at: Darul A'asima linNashr'e wat-Tozee'i, P. 261

${ }^{51}$ Al-Mujam Al-Awsat, Vol: 6, P. 183, Hadith No. 6133

${ }^{52}$ Al-Tarikh Al-Kabir, Al-Bukhari, Vol: 2, P. 278

53 Al-Duafa, Al-Uqaili, Vol: 1, P. 575

${ }^{54}$ Musnad Al-Bazzar, Vol: 14, P. 9, Hadith No. 7388

${ }^{55}$ Sunan Al-Daraqutni, Ali ibn Umar Al-Daraqutni, Abu Al-Hasan, Edited by: Shu'aib Al-Arna'ut, Hasan Abdul Mun'em Shalabi, Abdul Latif Hirz Ullah Barhum, Published at: Mu'assa Al-Risala, Beirut, 1423 AH, Vol: 1, P. 76, Hadith No. 132

${ }^{56}$ Al-Jarhu' wat-Ta'adeel, Al-Razi, Vol: 3, P. 85 


$$
\begin{aligned}
& \text { أما الحارث بن عبيد أبو قدامة؛ فهو الإيادي، مؤذن مسجد البرتي، أخرج له البخاري } \\
& \text { (57) } \\
& \text { تعليقا، ومسلم وأبو داود والترمذي. }
\end{aligned}
$$

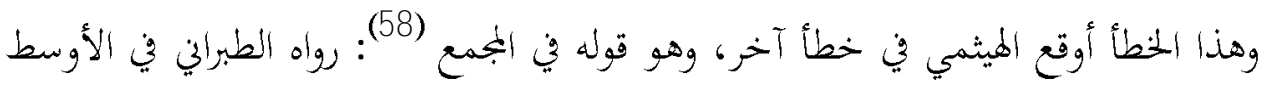

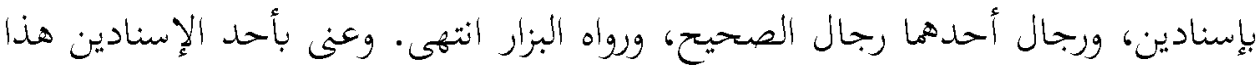

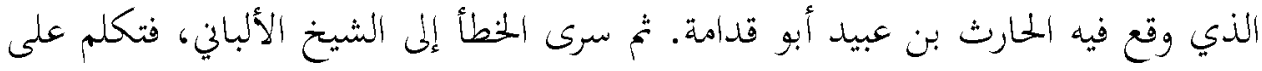

$$
\begin{aligned}
& \text { الحارث بن عبيد؛ ثم تبين له أن الصواب فيه: الحارث بن غسان، ونهان وهو خطأ في نسخة } \\
& \text { الأوسط للطبراني. }
\end{aligned}
$$

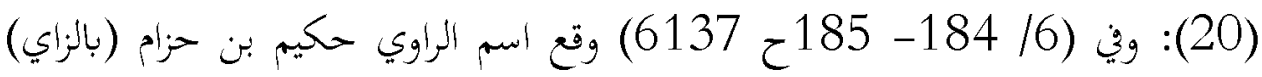

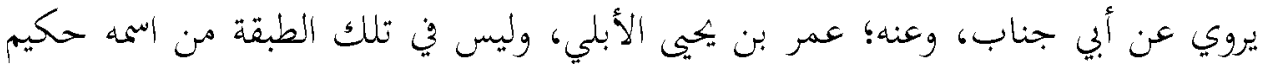

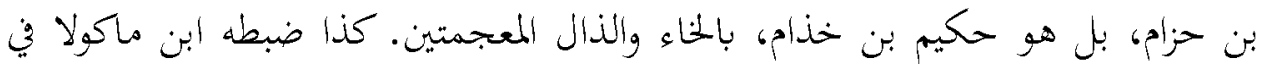

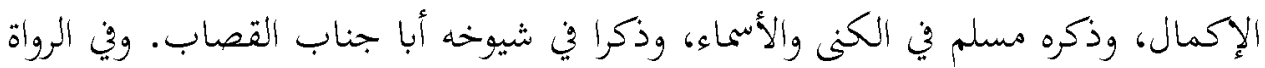

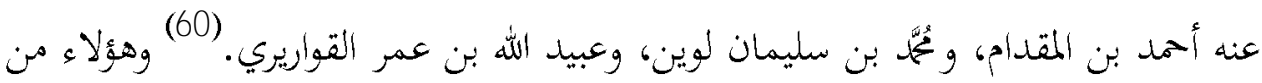

$$
\begin{aligned}
& \text { طبقة عمر بن يميى الأبلي الواقع في الإسناد. }
\end{aligned}
$$

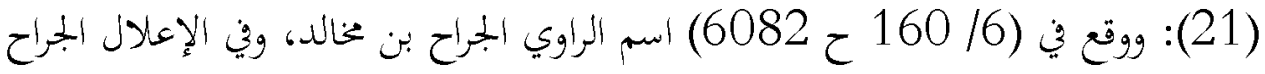

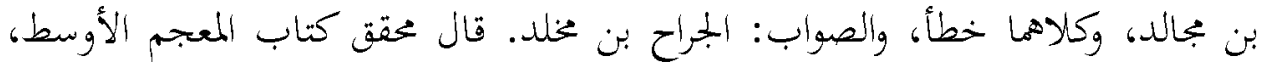

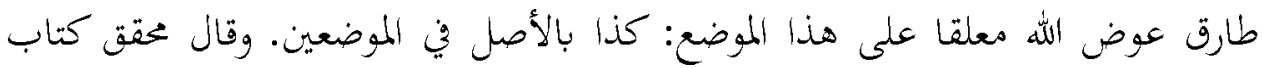

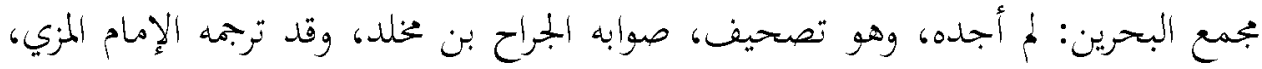

${ }^{57}$ Taqreebu' Al-Tahzeeb, Ibn Hajar, P. 212

${ }^{58}$ Majma Al-Zawa'id, Al-Haythami, Vol: 10, P. 350

${ }^{59}$ Silsilatul Al-Ahadith' ud-Dha'efa, Vol: 11, P. 255- 257, Hadith No. 5154

60 Al-Kuna wal-Asma'a, Muslim bin Al-Hajjaj Al-Qushairi, Edited by:

Abd Ur-Rahim Muhammad Ahmad Al-Qashqari, Published at: Islamic University, Madinah, and Al-Ikmal fi raf'e Al-Irtiyab anil-Mu'utalaf wal Mukhtalaf fi Al-Asma'a wal Kuna, Ali bin Hiba't Ullah bin Abu Nasr bin Ma'akula, Published by: Darul Kutub Al-Elmiya, Beirut, 1411 AH, Vol: 2, P. 419 


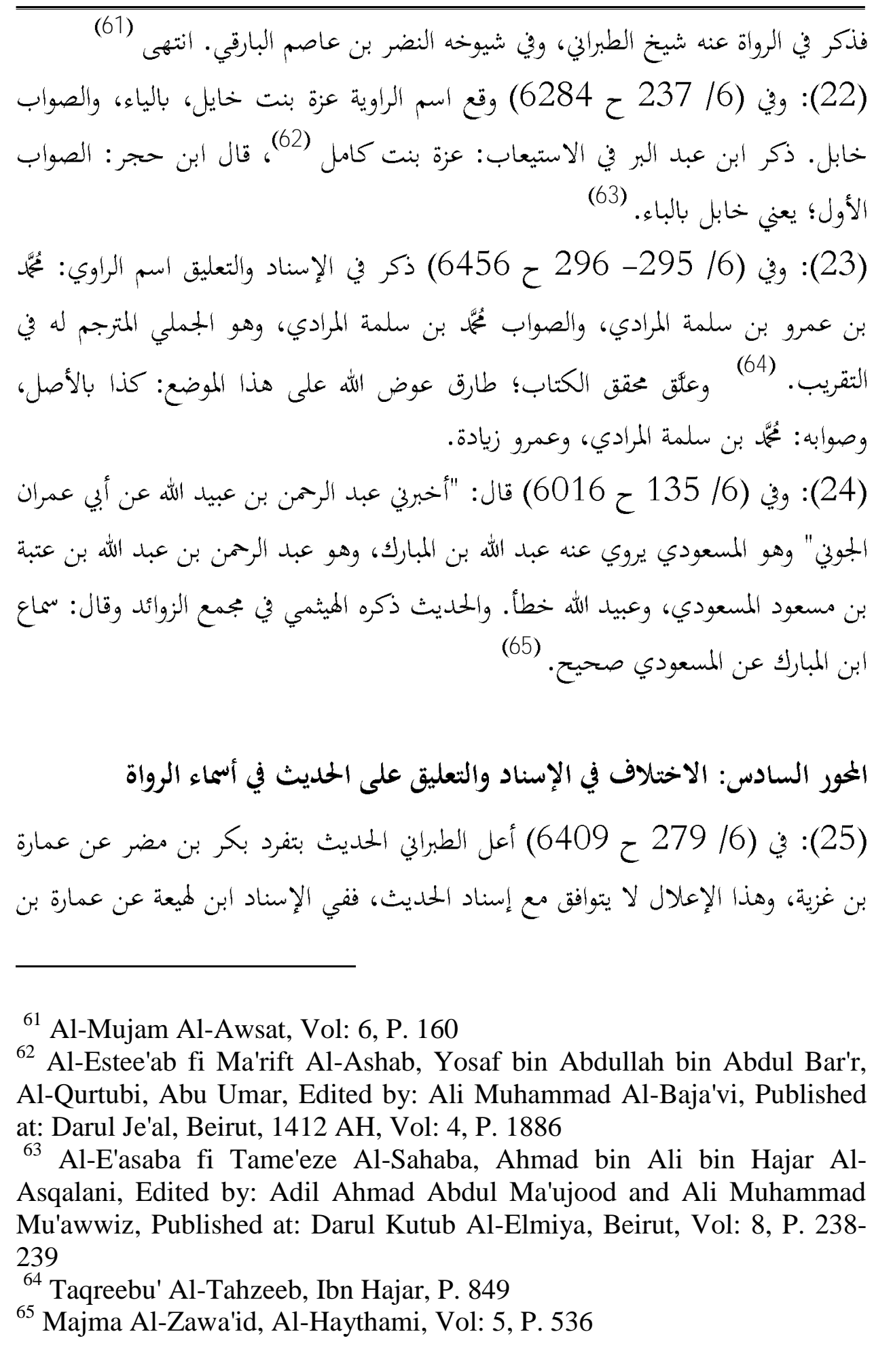


غزية. وعلق محقق كتاب المعجم الأوسط على هذا الموضع بأن بكر بن مضر من أقران ابن

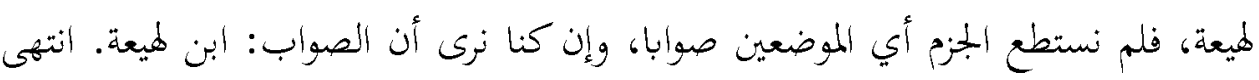

(26): في (6/ 157 ح 6072) أخرج الحديث من طريق عثمان بن الهيثم المؤدب عن

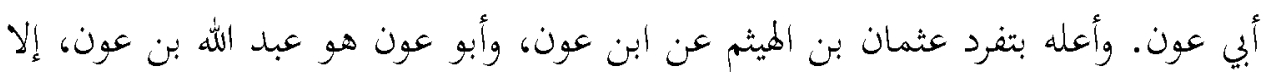

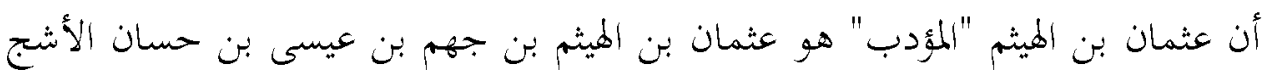
البصري العبدي المؤذن (67)، وليس المؤدب، فالصواب المؤذن.

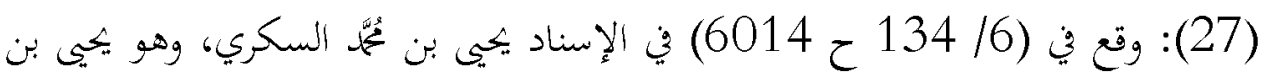

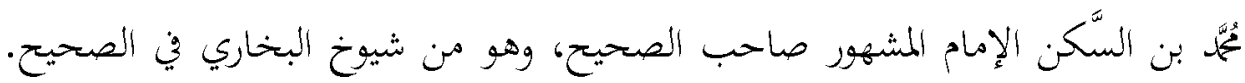

(28): وفي (6/ 175 ح 6112) قال في الإسناد: عبد الله المخرمي، وفي التعليق قال:

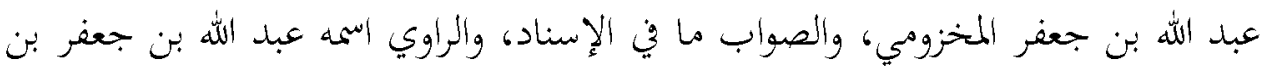

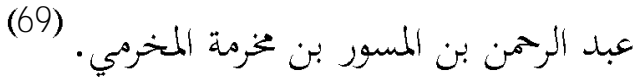

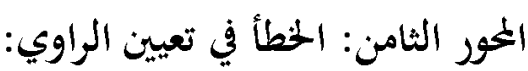

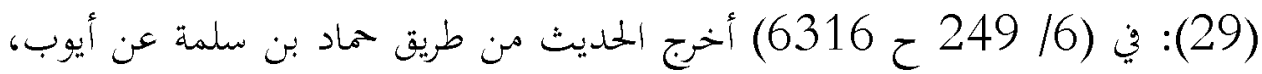

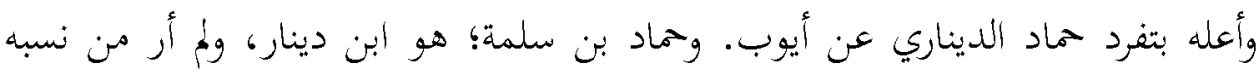

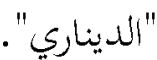

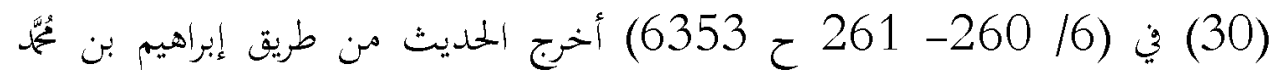

\footnotetext{
${ }^{66}$ Al-Mujam Al-Awsat, Vol: 6, P. 279

${ }^{67}$ Taqreebu' Al-Tahzeeb, Ibn Hajar, P. 670

${ }^{68}$ Taqreebu' Al-Tahzeeb, Ibn Hajar, P. 1065

${ }^{69}$ Taqreebu' Al-Tahzeeb, Ibn Hajar, P. 496
} 


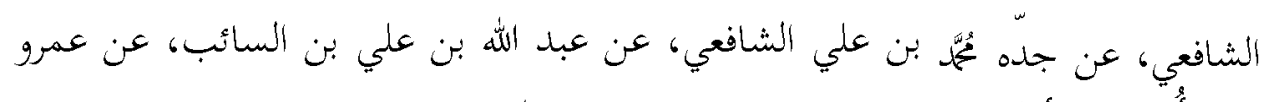

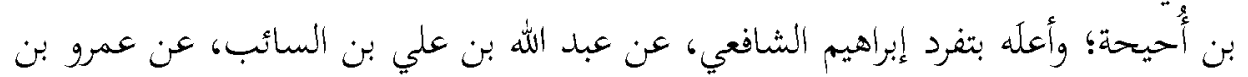

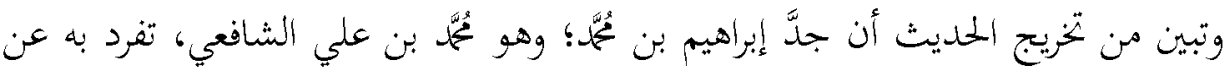

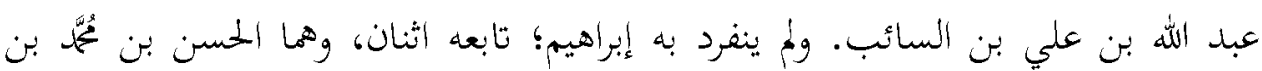

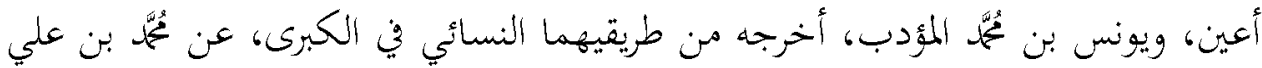

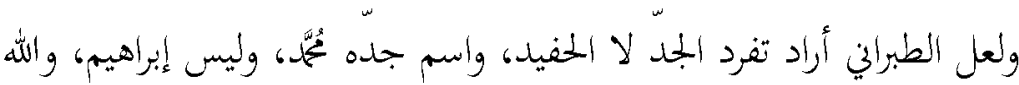

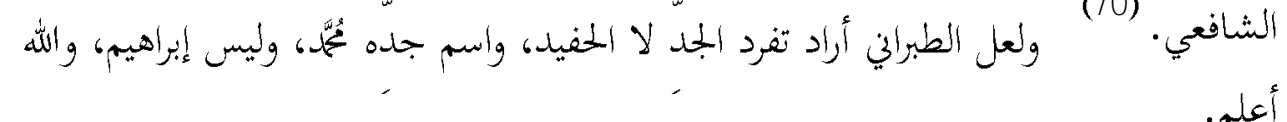

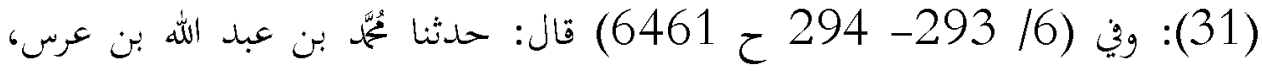

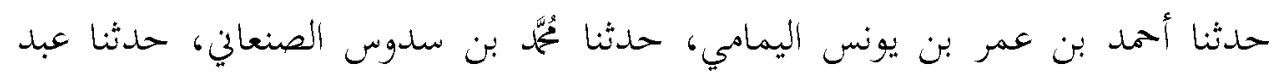

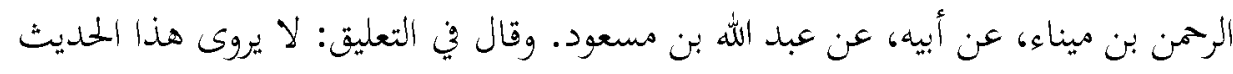

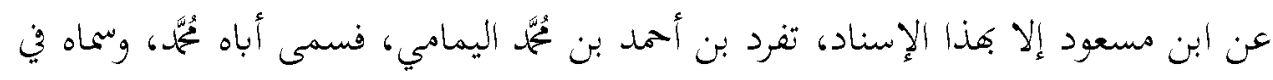

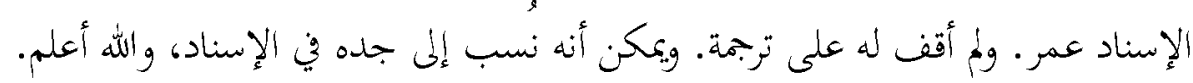

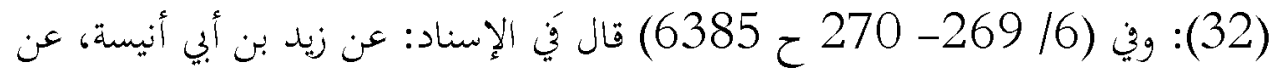

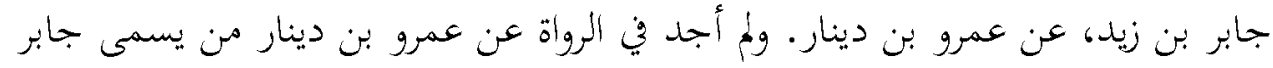

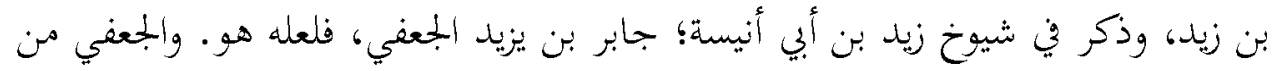

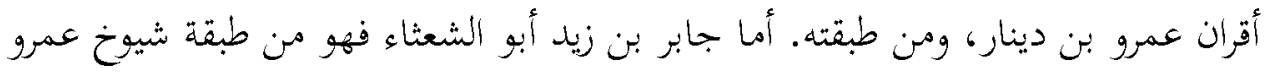$$
\text { بن دينار، والله أعلم. }
$$

(33): وفي (6/ 277 ح 2403) أعل الحديث بالاختاف عن الزهري، فذكر أن

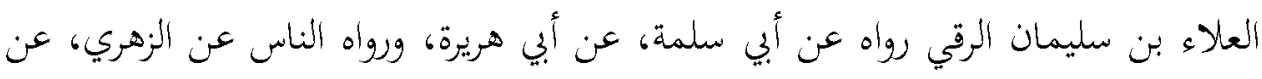

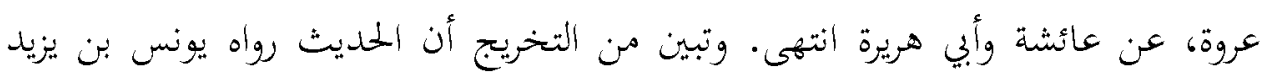

${ }^{70}$ Sunan An-Nasa'i Al-Kubra, Vol: 8, P. 194, Hadith No. 8943, Vol: 8, P. 195, Hadith No. 8945 


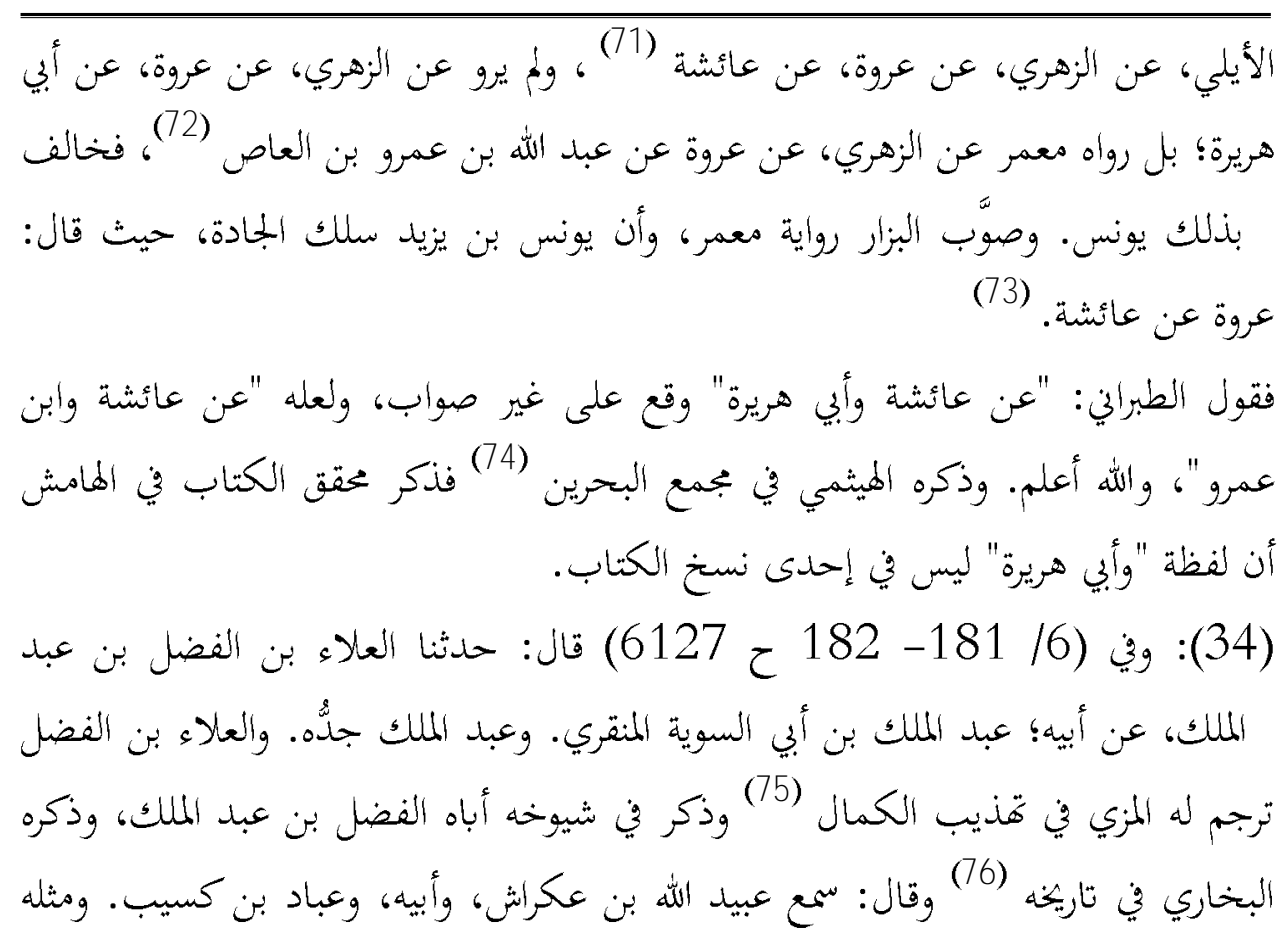

71 Musnad Al-Bazzar, Vol: 18, P. 141, and Shar'ah Mushkil Al-A'athar, Ahmad bin Muhammad Al-Thahavi, Abu Ja'afar, Edited by: Shu'aib AlArna'ut, Published at: Mu'assa Al-Risala, Beirut, 1415 AH, Vol: 1, P. 284285, Hadith No. 318, and Mu'jam ibnul A'ara'abi, Ahmad bin Muhammad, Ibnul Ar'ara'abi, Abu Saeed, Edited by: Abdul Muhsin A-Husaini, Published at: Dar-e-Ibnul Ja'wzi, Saudi Arabia, 1418 AH, Vol: 2, P. 484, Hadith No. 937

${ }_{72}$ Musnad Al-Bazzar, Above Page

73 Nuzhatul Alba'ab fi Qa'ulet-Tirmizi "Wa fil-Ba'ab", Hasan bin Muhammad As-Sana'ani, Abu Al-Fazal, Published at: Dar-e-Ibnel Ja'wzi, Saudi Arabia, 1426 AH, Vol: 6, P. 3322

${ }^{74}$ Majma'ul Bahrain fi Zawaid Al-Mu'jamain, Edited by: Abdul Quddos bin Muhammad Nazir, Published at: Maktabah Al-Rushd, Riyadh, 1413 AH, Vol: 1, P. 282, Hadith No. 333

${ }^{75}$ Tahzeeb Al-Kamal, Vol: 22, P.530

${ }^{76}$ Al-Tarikh Al-Kabir, Al-Bukhari, Vol: 6, P. 513 


$$
\begin{aligned}
& \text { قال ابن حبان في المجروحين. (77) ولم أجد لأبيه ترجمة. وإطلاق الأب على الجدد في هذا }
\end{aligned}
$$

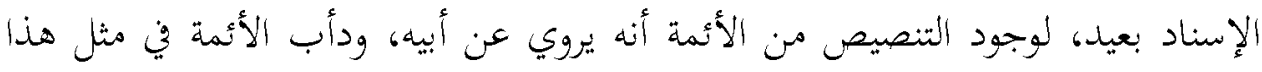

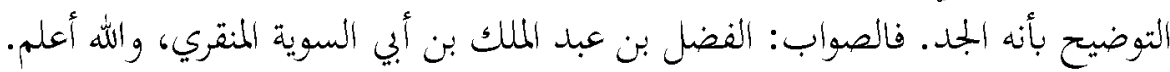

$$
\begin{aligned}
& \text { المحور التاسع: الزيادة في الإسناد والصواب عدمها: } \\
& \text { (35): في (16 } 164 \text { ح 6088) وقع في الإسناد "نا يُمَّمُ بن الحسين بن المبارك، عن }
\end{aligned}
$$

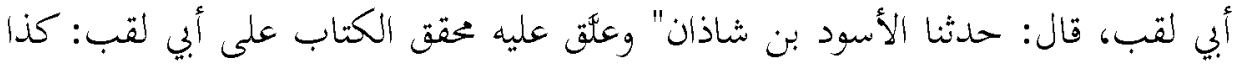

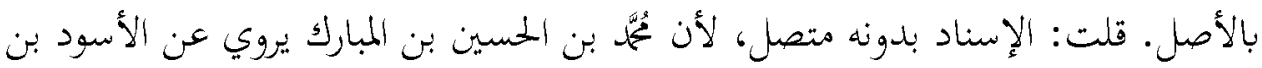

$$
\begin{aligned}
& \text { شاذان كما في ترجمته في تاريخ بغداد. }
\end{aligned}
$$

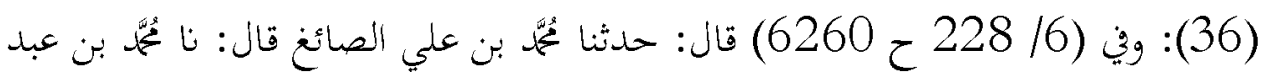

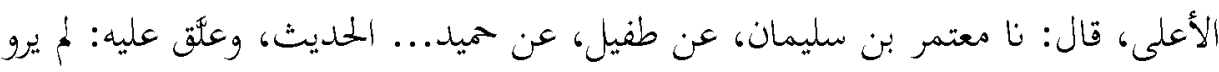

$$
\begin{aligned}
& \text { هذا الحديث عن حميد إلا طفيل شيخ بصري، تفرد به معتمر. }
\end{aligned}
$$

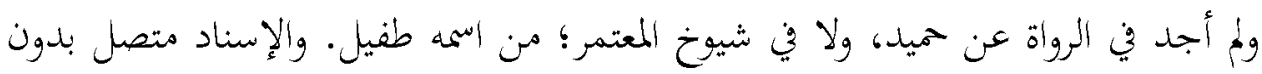

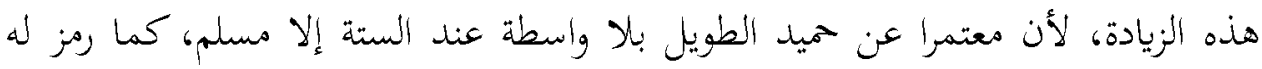

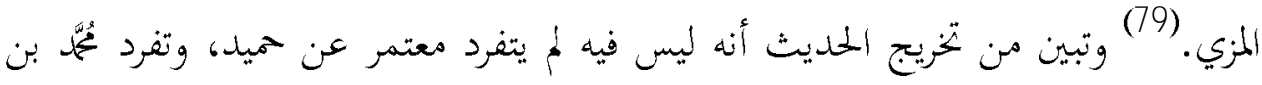

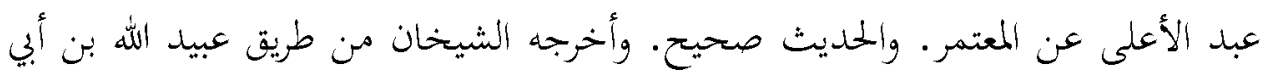

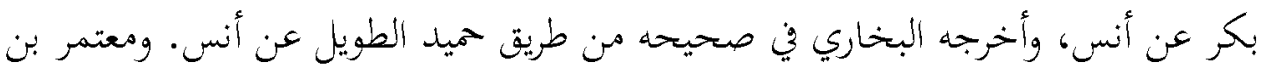

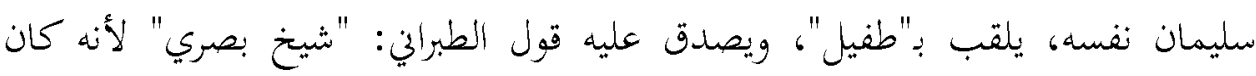

$$
\begin{aligned}
& \text { بصريا. فلعله أراد معتمرا لكن الصواب في الإعلال تسميته الأصلية، والله أعلم. }
\end{aligned}
$$

${ }^{77}$ Al-Majroheen, Muhammad bin Hibban Al-Tameemi, Abu Ha'atam, AlBusti, Edited by: Mahmood Ibrahim Za'aid, Published by: Darul Wa'ee, Aleppo, 1396 AH, Vol: 2, P. 183

78 Tatikh Baghdad, Ahmad bin Ali Al-Khateeb Al-Baghdadi, Abu Bakr, Edited by: Dr. Basshar Awad Ma'aroof, Published at: Darul Gharb AlIslami, Beirut, $1422 \mathrm{AH}$, Vol: 3, P. 8

${ }^{79}$ Tahzeeb Al-Kamal, Vol: 28, P. 250- 256 


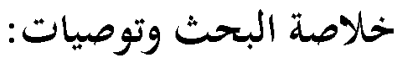

تبين محا سبق أن:

ل الأخطاء وقعت في المعجم الأوسط للإمام الطبراني.

ل الكاشف عن هذه الأخطاء دراسة تلك الأحاديث من جهة علم التخريج والعلل.

ل جل الأخطاء في أسماء الرواة وأسماء آبائهم، ونسبهم، وبعضها في إبدال الراوي

غيره، أو الزيادة والسقط من الإسناد.

نسبة الأخطاء في الكتاب 2. \%7\% في أحاديث الكتاب.

يوصي الباحث طلاب الحديث أن يدرسوا الكتاب من هذه الجهة، وهذا الموضوع

يصلح في مرحلة الدكتوراه في الحديث وعلومه. 